\title{
Magnetic Deflection Coefficient Investigation for Low Energy Particles
}

\author{
Ibrahim G. Faiadh* \\ Faisal G. Hamudy*
}

\author{
Muhammad I. Ismaeel* \\ Saad S. Dawood*
}

Received 6, December, 2009

Accepted 14, June, 2010

\begin{abstract}
:
In this research we solved numerically Boltzmann transport equation in order to calculate the transport parameters, such as, drift velocity, $\mathrm{W}, \mathrm{D} / \mu$ (ratio of diffusion coefficient to the mobility) and momentum transfer collision frequency $v_{\mathrm{m}}$, for purpose of determination of magnetic drift velocity $\mathrm{W}_{\mathrm{M}}$ and magnetic deflection coefficient $\psi$ for low energy electrons, that moves in the electric field $\mathrm{E}$, crossed with magnetic field $\mathrm{B}$, i.e; $\mathrm{E} \times \mathrm{B}$, in the nitrogen, Argon, Helium and it's gases mixtures as a function of: $\mathrm{E} / \mathrm{N}$ (ratio of electric field strength to the number density of gas), $\mathrm{E} / \mathrm{P}_{300}$ (ratio of electric field strength to the gas pressure) and $\mathrm{D} / \mu$ which covered a different ranges for $\mathrm{E} / \mathrm{P}_{300}$ at temperatures $300^{\circ} \mathrm{k}$ (Kelvin).

The results showed had been tabulated and graphically represented as functions of their variables. These results a satisfactory agreement between experimental values and theoretical data given in the literature showed.
\end{abstract}

Key words: Boltzmann transport equation, Electron energy distribution, molecular transport data.

\section{Nomenclature}

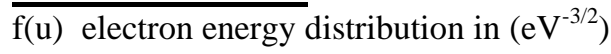

$\mathrm{u} \quad$ electron energy in $\mathrm{eV}$

e electron charge in coulomb

$\mathrm{m}$ electron mass in gm

M molecular mass

$\mathrm{Tg}$ gas temperature in Kelvin $\left({ }^{\circ} \mathrm{k}\right)$

$\mathrm{E} / \mathrm{N}$ ratio of the electric field to the gas $\operatorname{density}\left(\mathrm{V} \mathrm{cm}{ }^{2}\right)$

$\sigma_{\mathrm{c}}$ momentum transfer cross section in $\mathrm{cm}^{2}$

$\sigma_{\mathrm{ij}}$ inelastic cross section in $\mathrm{cm}^{2}$

$\mathrm{V}_{\mathrm{ij}}$ threshold energy eV

$\delta_{i}$ relative number of the molecules in the ith state

$\mathrm{B}_{\mathrm{o}}$ rotational constant in $\mathrm{eV}$

$\sigma_{o}=8 \pi q^{2} a_{o}^{2} / 15$ electric quadrupole moment in unit of $e a_{o}^{2}$ and $q=1.01$

$\mathrm{a}_{\mathrm{o}}$ Bohr radius

$\mathrm{x}$ the subscript $\mathrm{x}$ represents the various states

$\delta$ represent only the fractional populations in the various $v$-levels of the $x^{1} \sum_{g}^{+}$state

$\mathrm{N}_{v}$ represent the number density of the molecules in the $v$ th level

$\mathrm{n}_{\mathrm{e}}$ electron number density in $\mathrm{cm}^{-3}$

C.P.Q. are represent the rate coefficients for the e-V,V-T and V-V energy exchange processes in $\left(\mathrm{cm}^{3}\right.$ $\mathrm{S}^{-1}$ )

$\mathrm{R}(\mathrm{v})$ the rate of atomic recombination into the uth level

$\mathrm{r}(\mathrm{v})$ distribution satisfying the $\sum_{v} r(v)=1$

\footnotetext{
*Ministry of Science \& Technology
} 


\section{Introduction:}

The motion of the electrons swarming in the crossed electric field with magnetic fields had been investigated for many years, firstly they had been studied experimentally by two Scientist Townsend and Tizard 1913, which is used the measurement method of electrons drift velocities and more recently from this, it is find detailed examinations of motions of electrons swarms under this conditions (e.g. Huxly 1960) have shown the electron drift velocity can not be deduced in simple way from the results of such measurements, on the other hand, it has under certain circumstances measurements in crossed afford valuable formation about the energy dependence of the momentum transfer cross section or the form of energy distribution, as a consequence there is renewed interest in making such as measurements for this type. The experiments initiated of this type by Townsend developed by Huxley, a uniform electric field is applied along the axis together with magnetic field along the other axis.

There is a modern measurements achieved by Jory 1965 for calculation of magnetic deflection coefficient and magnetic drift velocity for nitrogen gas and for the case of helium gas by Crompton, Elford and Jory 1967......e.t.c.[1-4].

The early experiments were designed specially to measure drift velocity and data were obtained from this experiments it is a unique for many years because the time-of-flight methods is limited, the only variation data for electron drift velocities at high variation of $\mathrm{E} / \mathrm{P}$ (electric field strength to the gas pressure ratio) are derived from such type, experiments, which is achieved by Townsend 1937, there are difficulties in deducing precise values of drift velocity from the experiments. When the Townsend used the first method he deduced a simple relation between angular drifties of the electrons stream and drift velocity shows all the electrons in the swarm have the same agitational speed, if proper account were taken for the distribution of speeds within the swarm, the drift velocity deduced from the simple formula had to be multiplied by a factor usually near unity, the magnitude of the factor depending on the form of energy distribution assumed.

From the above data we can find from drift velocity $\mathrm{W}_{\mathrm{M}}$ measured by a magnetic deflection technique only by multiplying by a dimensionless factor, which is the Huxly 1960 derived a rigorous relationship between $\mathrm{W}, \mathrm{W}_{\mathrm{M}}$ and that the coefficient $\mathrm{C}$ in the relation [5]:

$\mathrm{W}=\mathrm{CW}_{\mathrm{M}}$

where, depends directly on the variation of the momentum transfer cross section with electron energy, as well as, indirectly through its effect on distribution of electron energies.

\section{Theoretical Formulation:}

We use the homogeneous Boltzmann equation in the steady state as derived from the usual two-term expansion in spherical harmonics which can be written as [6]:

$\frac{d}{d u}\left[\frac{1}{3}\left(\frac{E}{N}\right)^{2} \frac{u}{\sigma_{c}} \frac{d f}{d u}+\frac{2 m}{M} \sigma_{c} u^{2}\left(f+\frac{k T_{g}}{e} \frac{d f}{d u}\right)+4 B_{o} \sigma_{o} u f\right.$

$=\sum_{i, j} \delta_{i}\left[u f(u) \sigma_{i j}(u)-\left(u+V_{i j}\right) f\left(u+V_{i j}\right) \sigma_{i j}\left(u+V_{i j}\right)\right]+$

$\sum_{j, i} \delta_{j}\left[u f(u) \sigma_{j i}(u)-\left(u-V_{i j}\right) f\left(u-V_{i j}\right) \sigma_{j i}\left(u-V_{i j}\right)\right]$

The first two terms on the right-hand side of eq.(2) refer to the rate of change of the total electron flux at energy u caused by inelastic collisions of the first kind, the first term calculates the removal of electrons, the second one accounts for the 
introduction (reintroduction and the removal of electron as a result of electron impact excitation). The last two terms on the right account for the similar effects caused by inelastic collisions of the second kind (also termed superelastic collisions). Here $\mathrm{f}(\mathrm{u})$ is normalized such as:

$$
\int_{0}^{\infty} f(u) u^{\frac{1}{2}} d u=1
$$

\section{Numerical procedure:}

To solve the eq.(2) the right-hand side of eq.(2) the contribution of excitation to electronic states reduces to:

$\sum_{x} u \sigma_{x}(u) f(u)-\sum_{x}\left(u+V_{x}\right) \sigma_{x}\left(u+V_{x}\right) f\left(u+V_{x}\right) .$.

Hence

$\delta_{v}=N_{v} / N$

$\sum_{v} \delta_{v}=1$

We know that eq.(2) is coupled through the $\delta_{\mathrm{v}}$ to the system of steady state rate balance equations for the vibrational levels. The equation for the vth level may be written:

$$
\begin{aligned}
& n_{e} \sum_{w=0, w \neq v}^{n} N_{w} C_{w, v}-n_{e} N_{v} \\
& \sum_{w=0, w \neq q_{v}}^{n} C_{v}+N_{v-1} N P_{v-1, v}+N_{v+1} N P_{v+1, v} \\
& -N_{v}\left(P_{v, v-1}+P_{v, v+1}\right) \\
& +N_{v-1} \sum_{w=0}^{n-1} N_{w+1} Q_{v-1, v}^{w+1, w} \\
& +N_{v+1} \sum_{w=0}^{n} N_{w} Q_{v+1, v}^{w, w+1} \\
& -N_{v}\left(\sum_{w=0}^{n-1} N_{w+1} Q_{v, v+1}^{w+1, w}+\sum_{w=0}^{n} N_{w} Q_{v, v-1}^{w, w+1}\right) \\
& +R(v)=0 \quad \ldots . . .(7)
\end{aligned}
$$

The e-V, V-T and V-V processes considered in eq.(7) which is:

$$
e-V \quad e+N_{2}(v) \underset{C_{v, w}}{\stackrel{C_{w, v}}{\rightleftharpoons}} e+N_{2}(w)
$$

$$
V-T\left\{\begin{array}{l}
N_{2}+N_{2}(v) \stackrel{P_{v-1, v}}{\underset{P_{v, v-1}}{\leftrightarrows}} N_{2}+N_{2}(v-1) \\
N_{2}+N_{2}(v+1) \stackrel{P_{v, v+1}}{\underset{P_{v+1, v}}{\leftrightarrows}} N_{2}+N_{2}(v)
\end{array}\right.
$$

$$
V-V\left\{\begin{array}{l}
N_{2}(v)+N_{2}(w) \frac{Q_{v-1, v}^{w+1, w}}{Q_{v, v-1}^{w, w+1}} N_{2}(v-1)+N_{2}(w+1) . .(11) \\
N_{2}(v+1)+N_{2}(w) \frac{Q_{v v, v+1}^{w+1, w}}{\frac{Q_{v+1, v}^{w, w+1}}{w+w}} N_{2}(v)+N_{2}(w+1) . .(12)
\end{array}\right.
$$

The total recombination rate $\Sigma_{v} \mathrm{R}(\mathrm{v})$ in eq.(7) must equal the total dissociation rate by the $\mathrm{V}-\mathrm{T}$ and $\mathrm{V}-\mathrm{V}$ processes into a pseudo level. The system of eq.(7) consists of 46 equations for $0 \leq v \leq 45, v=n+1=46$, as follow:-

$$
\begin{aligned}
v_{d}^{V} & =v_{d}^{V-T}+v_{d}^{V-V} \\
& =N^{2} \delta_{45}\left(P_{45,46}+\sum_{w=0}^{44} \delta_{w+1} Q_{45,46}^{w+1, w}\right) \ldots
\end{aligned}
$$

$R(v)=v_{d}^{V} r(v) \ldots . .(14)$

Where, $r(v)$ refer a distribution satisfying the condition $\sum_{v} r(v)=1$, since, $r(0)=1 ; r(v>0)=0$.

When the all collisional data from electron transport and scattering data, such as, excitation cross sections, total ionization cross sections, momentum transfer cross section, vibrational cross section and electronical cross section .e.t.c., in equation (2) and equation (7) these can solved to yield the electron energy distribution and $\mathrm{f}(\mathrm{u})$ as a function of the parameter $\mathrm{E} / \mathrm{N}$ [7].

\section{Basic Input Data and Calculations:}

The basic approach used for solving the Boltzmann equation consisted in converting it in a set of K-coupled algebraic equations by finite differencing the electron energy axis into $\mathrm{K}$ cells [8]. This set was solved by 
matrix inversion. By using [9], we can calculate electron diffusion motion parameters, such as, drift velocity $\mathrm{W}$, characteristic energy $D / \mu$ and momentum transfer collision frequency $v_{\mathrm{m}}$ as seen in Tables (1-7).

\section{Derivation of Equation for $\psi$ :}

The experiments which is the scientific are performed it's uniform electric field $\mathrm{E}$ applied along $\mathrm{Z}$-axis which together uniform magnetic field $\mathrm{B}$ applied along $\mathrm{y}$-axis, the quantity has obtained experimentally it's $\mathrm{W}_{\mathrm{x}} / \mathrm{W}_{\mathrm{z}} \quad$ (the ratio of the transverse drift velocity $\mathrm{W}_{\mathrm{x}}$ longitude drift velocity $\mathrm{W}_{\mathrm{z}}$ ), this ratio is a function of $\mathrm{E} / \mathrm{N}$ (electric field strength to the gas number density ratio) and is a function of $\mathrm{B} / \mathrm{N}$ too, (magnetic field strength to the gas number density ratio). At absent of the magnetic field, the drift velocity becomes constant and the uniform electric field $E$ is parallel to the $\mathrm{z}$-axis can be calculated from the relation [1]:

$\mathrm{W}=\mathrm{W}_{\mathrm{z}}$

$$
=-\frac{4 \pi E e}{3 N m} \int_{0}^{\infty} \frac{c^{2} d f(c)}{q_{m} d c} d c \ldots .(15)
$$

Where e represents the electronic charge, $\mathrm{m}$ is the mass of electron, $\mathrm{q}_{\mathrm{m}}$ is momentum transfer cross section and f(c) represents the electrons distribution function has a velocity $c$. But at present the magnetic field $\mathrm{B}$ is applied a long $\mathrm{y}$-axis the stream mass center velocity is given by the relation:-

$\mathrm{W}=\mathrm{W}_{\mathrm{z}}+\mathrm{iW}_{\mathrm{x}}$

$$
W=-\frac{4 \pi E e}{3 N m} \int_{0}^{\infty} \frac{c^{2}}{q_{m}\left(1-i \frac{\omega}{v_{m}}\right)} \frac{d f(c)}{d c} d c \ldots . .(16)
$$

Where

$$
\begin{gathered}
\omega=\frac{e B}{m} \\
v_{m}=N q_{m} c
\end{gathered}
$$

Since $\omega$ represents the cyclotron frequency and $v_{\mathrm{m}}$ represents momentum transfer collision frequency.

From equation (16) if $\omega<<v_{\mathrm{m}}$ :-

$$
\begin{aligned}
& W_{x} \approx-\frac{4 \pi E e}{3 N m} \frac{B e}{N m} \int_{0}^{\infty} \frac{c}{q_{m}^{2}} \frac{d f(c)}{d c} d c . \\
& W_{z} \approx-\frac{4 \pi E e}{3 N m} \int_{0}^{\infty} \frac{c^{2}}{q_{m}} \frac{d f(c)}{d c} d c=W .
\end{aligned}
$$

and therefore

$\frac{W_{x}}{W_{z}} \approx \frac{B e}{N m}\left\{\int_{0}^{\infty} \frac{c}{q_{m}^{2}} \frac{d f(c)}{d c} d c\right\}\left\{\int_{0}^{\infty} \frac{c^{2}}{q_{m}} \frac{d f(c)}{d c} d c\right\}^{-1}$.

We can define $\mathrm{W}_{\mathrm{M}}$ :

$W_{M}=\frac{E}{B} \frac{W_{x}}{W_{z}}$

It follows that the magnetic drift velocity $\mathrm{W}_{\mathrm{M}}$ as defined by equation (22) is given by:-

$W_{M}=\frac{e E}{N m}\left\{\int_{0}^{\infty} \frac{c}{q_{m}^{2}} \frac{d f(c)}{d c} d c\right\}\left\{\int_{0}^{\infty} \frac{c^{2}}{q_{m}} \frac{d f(c)}{d c} d c\right\}^{-1}$

If $W_{M} \geq W$,i.e. $\psi \geq 1$

While the magnetic deflection coefficient is $\psi$ given by:-

$$
\begin{aligned}
\Psi & =\frac{W_{M}}{W}=\left(\frac{E}{B}\right)\left(\frac{W_{x}}{W_{z} W}\right) \\
& \approx\left(\frac{E}{B}\right)\left(\frac{W_{x}}{W^{2}}\right)
\end{aligned}
$$

if $\mathrm{W}_{\mathrm{M}}=\mathrm{W}$, i.e.

$$
\approx-\frac{3}{4 \pi}\left\{\int_{0}^{\infty} \frac{c}{q_{m}^{2}} \frac{d f(c)}{d c} d c\right\}\left\{\int_{0}^{\infty} \frac{c^{2}}{q_{m}} \frac{d f(c)}{d c} d c\right\}^{-2} .
$$

$\psi=1$

\section{Calculations:}

We constructed a Fortran program to calculate the following transport coefficient parameters as seen in Tables(8-16):

\section{1-E/P parameter:}

From the relation we can convert unit of $\mathrm{E} / \mathrm{N}$ in unit of $\mathrm{E} / \mathrm{P}$ :-

$$
\frac{E}{P}=\frac{E}{N} \times 967 \times 10^{16} \frac{1}{{ }^{\circ} T}
$$

2-Magnetic drift velocity 
We can find the magnetic drift velocity from the following mathematical relation [10]:

$$
W_{M}=\frac{e}{m} \frac{E}{v_{m}}
$$

Where, $\quad \mathrm{e}=1.602 \times 10^{-19}$ $\mathrm{m}=9.109 \times 10^{-31} \mathrm{~kg}$

$$
\begin{aligned}
\frac{e}{m} & =1.759 \times 10^{11} \frac{\mathrm{C}}{\mathrm{kg}} \\
& =1.759 \times 10^{11} \frac{\mathrm{C}}{10^{3} \mathrm{gm}} \\
& =1.759 \times 10^{8} \mathrm{Cgm}^{-1} \\
E & =\frac{V}{\mathrm{~cm}} \\
v_{\mathrm{m}} & =\mathrm{s}^{-1}
\end{aligned}
$$

$\mathrm{C}$ and

Where $\mathrm{E}$ represents the electric field in Volt $(\mathrm{V}) / \mathrm{cm}, \quad v_{\mathrm{m}}$ is the momentum transfer collision frequency.

Substituting eq.(25) in eq.(24) yield:-

$$
\begin{aligned}
W_{M} & =1.759 \times 10^{8} \frac{C}{g m} \frac{E}{v_{m}} \\
& =1.759 \times 10^{8} \frac{C}{g m} \frac{E \frac{C m}{v_{m} s^{-1}}}{=} \\
& =1.759 \times 10^{8} \frac{E}{v_{m}} \frac{C V s}{g m c m}
\end{aligned}
$$

3-Units conversation:

We know the magnetic drift velocity $\mathrm{W}_{\mathrm{M}}$ measured in unit of $\mathrm{cm} / \mathrm{s}$, but from eq.(26) there are deferent unit since conversation requirement this unit to $\mathrm{cm} / \mathrm{s}$ which is we can defend the force (F), represent product electric field strength (E) by coulomb charge (q) which is:-

$\mathrm{F}=\mathrm{E} \mathrm{q}$

Where $(\mathrm{F})$ measured in Newton $(\mathrm{N})$, (q) in unit of coulomb (C) and electric field in unit of volt $/ \mathrm{m}$, since convert those into eq.(27) yield:-

$$
\begin{aligned}
& F(N)=E\left(\frac{V}{m}\right) q(C), \text { In terms of } \\
& N=\frac{V C}{m} \\
& N m=V C \quad \text {.....(28) }
\end{aligned}
$$

$1 \mathrm{~N}=1 \mathrm{~kg} \mathrm{~m} \mathrm{~s}^{-2}$

Substitute eq.(29) into eq.(28) yield:-

$$
\mathrm{Kg} \mathrm{m} \mathrm{s}^{-2} \mathrm{~m}=\mathrm{V} \mathrm{C}
$$

Substitute eq.(30) into eq.(26) yield:-

$$
\begin{aligned}
& W_{M}=1.759 \times 10^{8} \frac{E}{v_{m}} \frac{\mathrm{Nms}}{\mathrm{gmcm}} \\
& =1.759 \times 10^{8} \frac{E}{v_{m}} \frac{\mathrm{kg} \mathrm{m} \mathrm{s}^{-2} \mathrm{~m} \mathrm{~s}}{\mathrm{gm} \mathrm{cm}}
\end{aligned}
$$

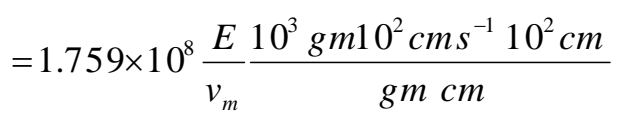

$$
\begin{aligned}
& =1.759 \times 10^{8} \times 10^{7} \frac{E}{v_{m}} \frac{\mathrm{cm}}{\mathrm{s}} \\
& =1.759 \times 10^{15} \frac{E}{v_{m}} \frac{\mathrm{cm}}{\mathrm{s}}
\end{aligned}
$$

4-Magnetic deflection coefficient $\psi$ :

We can find the Magnetic deflection coefficient $\psi$ in terms of transport coefficient which related through the equation [6]:-

$W=C\left(\frac{E}{B}\right)\left(\frac{W_{x}}{W_{z}}\right)$

Where $\mathrm{W}$ represent drift velocity, $\mathrm{c}$ is dimensionless factor, $\mathrm{E}$ is the electric field, $\mathrm{B}$ is the magnetic field, $\mathrm{W}_{\mathrm{x}} / \mathrm{W}_{\mathrm{z}}$ represents transverse \& longitude drift velocity for moving electrons in gases, and in electric field crossed with magnetic field.

We assume $\mathrm{W}_{\mathrm{M}}$ represent magnetic drift velocity according to the relation:-

$W_{M}=\frac{E}{B} \frac{W_{x}}{W_{z}}$

Substitute eq.(33) in eq.(325) yield:-

$W=C W_{M}$

We can say from eq.(34) the factor $C$ is dimensionless factor and depends on the change of momentum transfer cross section with electron energy and function of energy distribution, since less than unity, often more convenient to use the reciprocal of $\mathrm{C}$, which will be denoted by $\psi$ as in equation:-

$C^{-1}=\psi$......(35) 
Where $\psi$ is called the magnetic deflection coefficient and obtained by dividing the drift velocity $\mathrm{W}_{M}$ to real drift velocity $\mathrm{W}$ [13], which by dividing eq.(33) into eq.(32), it's yield:-

$$
\psi=\frac{(E / B)\left(W_{x} / W_{z}\right)}{C(E / B)\left(W_{x} / W_{z}\right)}
$$

Through eq.(35) yield:-

$$
\begin{aligned}
& C^{-1}=\frac{W_{M}}{W} \\
& \psi=C^{-1}=\frac{W_{M}}{W}
\end{aligned}
$$

Where $\mathrm{W}_{\mathrm{M}}$ refers to the magnetic drift velocity and $\mathrm{W}$ is drift velocity.

\section{List of Program: \\ $\mathrm{N}=11$ \\ DIMENSION EON(N), E(N), \\ $\mathrm{W}(\mathrm{N}), \mathrm{NU}(\mathrm{N})$ \\ DIMENTION EOP(N), WM(N), \\ PSI $(\mathrm{N})$ \\ OPEN(1,FILE='TABLE1.INP') \\ OPEN(2,FILE='TABLE1.OUT') \\ $\mathrm{EC}=1.602 \mathrm{E}-19$ \\ $\mathrm{EM}=9.109 \mathrm{E}-31$ \\ $\mathrm{TG}=300$ \\ $\mathrm{EOM}=\mathrm{EC} / \mathrm{EM}$ \\ DO $10 \mathrm{I}=1, \mathrm{~N}$ \\ $\operatorname{READ}\left(1,{ }^{*}\right) \mathrm{EON}(\mathrm{I}), \mathrm{E}(\mathrm{I}), \mathrm{W}(\mathrm{I}), \mathrm{NU}(\mathrm{I}), \mathrm{E}$ \\ OP(I) \\ $\mathrm{EOP}(\mathrm{I})=\mathrm{EON}(\mathrm{I}) * 967 \mathrm{E} 16 / \mathrm{TG}$ \\ $\mathrm{WM}(\mathrm{I})=\mathrm{EOM}(\mathrm{I}) * \mathrm{E}(\mathrm{I}) / \mathrm{NU}(\mathrm{I})$ \\ $\operatorname{PSI}(\mathrm{I})=\mathrm{WM}(\mathrm{I}) / \mathrm{W}(\mathrm{I})$ \\ WRITE(2,100)EON(I),EOP(I),WM(I), \\ PSI(I) \\ 10 CONTINUE \\ 100 FORMATE(4E10.3) \\ Stop \\ END}

\section{Results and Discussion:}

We studied the different cases for various gases to evaluate the magnetic deflection coefficient to them and compare it with the literature which appeared to be in a good agreement with it [1].
The figs.(1-4) show the values of magnetic deflection coefficient for pure $\mathrm{N}_{2}$, Ar, Ar-He- $\mathrm{N}_{2}$ and $\mathrm{Ar}-\mathrm{H}_{2}$ with percentages composition respectively are constant with increasing of the $\mathrm{E} / \mathrm{N}$ and $\mathrm{E} / \mathrm{P}$ values, As $\mathrm{E} / \mathrm{P}$ increase the energy distribution don't departs further from the Maxwellian form except the pure Helium gas, at values $\mathrm{E} / \mathrm{N}=4.6 \times 10^{-19} \quad$ V.cm ${ }^{2}, \quad$ and $\mathrm{E} / \mathrm{P}=1.48 \times 10^{-2} \quad$ V.cm ${ }^{-1} \quad$ Torr $^{-1}$, at $\mathrm{D} / \mu=0.04 \mathrm{eV}$, at $\mathrm{W}=0.88 \times 10^{5} \mathrm{~cm} / \mathrm{sec}$, there are rapidly increasing, after this point, then the deflection coefficient becomes constant.

The theoretical evaluation of $(\psi)$ depends on a knowledge of the variation of momentum transfer cross section with electron speed and of the distribution function $\mathrm{f}(\mathrm{c})$.

Fig(5) represents magnetic deflection coefficient $(\psi)$ as a function of the magnetic drift velocity, this shows all the values of the magnetic deflection coefficient for pure and mixtures gases are constant except for Helium gas at point $\mathrm{W}_{\mathrm{M}}=2.4 \times 10^{15} \mathrm{~cm} / \mathrm{sec}$ the magnetic deflection coefficient increases in a linear form, whenever the point $4.2 \times 10^{17} \mathrm{~cm} / \mathrm{sec}$ since $(\psi)$ becomes stable.

The coefficient $(\psi)$ is sensitive both of the variation of the momentum transfer cross section $\mathrm{q}_{\mathrm{m}}$ with electron energy and the form of the energy distribution function. For electron swarms in the monatomic gases in the energy regime in which only elastic collision, the form of the function is itself predominantly determined by the dependence of $\mathrm{q}_{\mathrm{m}}$ on electron speed $\mathrm{c}$, and for large fraction of the electrons in a swarm with this mean energy and compare it with those measured experimentally from equation (23) to calculate values of $(\psi)$ has been represented simply by [11]:-

$\mathrm{q}_{\mathrm{m}}=$ const. $\times \mathrm{c}^{\mathrm{r}}$

and the distribution function for the electron speeds by:- 
$\mathrm{f}(\mathrm{c})=$ const. $\exp \left[(-\mathrm{c} / \mathrm{a})^{\mathrm{n}}\right]$

where, $n=4+2 r$ and $r$ ranges between $(-1,0,1)$, in fact, the distribution is somewhat here narrower than the Druyvesteyn form, any differences between the values of $(\psi)$ at the same values of $D / \mu$ arise from differences in the forms of the energy distribution functions. From fig.(3) it can be seen that, the values of $(\psi)$ for the all gases are in close agreement except helium gas. Some differences between the energy distribution function for the gases for similar values of $D / \mu$ are to be expected because of differences in the power losses to rotational and vibration excitation in the gases. So we can show if $W_{M} \geq W$, i.e. $\psi \geq 1$, but when $W_{M}=W$, i.e. $\psi=1$ as shown in eq.(23).

Figs(6-7) represent the drift velocity as a function of the $\mathrm{E} / \mathrm{N}$ and $\mathrm{E} / \mathrm{P}_{300}$ respectively, this mean when electrons acquired more energy from the field, the drift velocity will increased. Which clear the drift velocity increasing for a pure gases and mixture percentages composition with the increasing of the $\mathrm{E} / \mathrm{N}$ and $\mathrm{E} / \mathrm{P}_{300}$ respectively.

Figs(8-9) show the values increasing of magnetic drift velocity with $\mathrm{E} / \mathrm{N}$ and $\mathrm{E} / \mathrm{P}_{300}$ respectively except for Helium gas at points $\mathrm{E} / \mathrm{N}=\left(4.6 \times 10^{-19}-1.2 \times 10^{-18}\right)$ V.cm ${ }^{2}, \mathrm{E} / \mathrm{P}_{300}=(0.04-0.07)$ V.cm ${ }^{-1}$ Torr 1 there are a rapidly increasing in magnetic drift velocity, this increasing in the $\mathrm{W}_{\mathrm{M}}$ because the electrons swarm have a more energy from the electric field.

Figs(10-11) show the pure Helium gas at points $\mathrm{E} / \mathrm{N}=\left(4.6 \times 10^{-19}-1.21 \times 10^{-}\right.$ $\left.{ }^{18}\right) \mathrm{V} . \mathrm{cm}^{2}$ and $\mathrm{E} / \mathrm{P}_{300}=(1.48-3.9) \times 10^{-2}$ V.cm ${ }^{-1}$ Torr $^{-1}$ there are a reducing in the values of momentum transfer collision frequency $\left(v_{m}\right)$ since the $v_{m}$ increases with increasing of the $\mathrm{E} / \mathrm{N}$ and $E / P_{300}$. But the values of $v_{m}$ for another pure gases and the mixture percentages composition to be increasing with $\mathrm{E} / \mathrm{N}$ and $\mathrm{E} / \mathrm{P}_{300}$, when $\left(v_{\mathrm{m}}\right)$ is constant, $\mathrm{W}_{\mathrm{M}}=\mathrm{W}$, so that $\psi=1$, but when the $f(c)$ is narrow the $(\psi)$ is equal to unity, regardless of the energy dependence of $\left(v_{m}\right)$.

Table (1):-The calculated electron diffusion motion parameters in pure Nitrogen gas

\begin{tabular}{|c|c|c|c|c|}
\hline$\underset{\left(\mathrm{V} \cdot \mathrm{cm}_{16}^{2}\right) \times 10^{-}}{\mathrm{E} / \mathrm{N}}$ & $\underset{(\mathbf{V} / \mathbf{c m})}{\mathbf{E}}$ & $\begin{array}{c}\mathrm{W} \\
(\mathrm{cm} / \mathrm{s}) \\
\times \mathbf{1 0} 0^{6}\end{array}$ & $\begin{array}{l}D / \mu \\
(\mathrm{eV})\end{array}$ & $\underset{\left(\mathrm{s}^{-1}\right) \times 10}{\mathbf{V}_{7}}$ \\
\hline 0.5 & 1335 & 1.09 & 0.786 & 0.0807 \\
\hline 1 & 2670 & 1.78 & 0.984 & 0.0987 \\
\hline 2 & 5340 & 3.06 & 1.144 & 1.15 \\
\hline 3 & 8010 & 4.18 & 1.247 & 1.26 \\
\hline 4 & 10680 & 5.08 & 1.352 & 1.38 \\
\hline 5 & 13350 & 5.75 & 1.477 & 1.53 \\
\hline
\end{tabular}

Table (2):-The calculated electron diffusion motion parameters in pure Argon gas

\begin{tabular}{|c|c|c|c|c|}
\hline $\begin{array}{c}\mathbf{E} / \mathbf{N} \\
\left(\mathbf{V} . \mathbf{c m}^{\mathbf{2}}\right) \times \mathbf{1 0}^{-\mathbf{1 8}}\end{array}$ & $\begin{array}{c}\mathbf{E} \\
(\mathbf{V} / \mathbf{c m})\end{array}$ & $\begin{array}{c}\mathbf{W} \\
(\mathbf{c m} / \mathbf{s}) \times \mathbf{1 0}^{\mathbf{5}}\end{array}$ & $\begin{array}{c}\mathbf{D} / \boldsymbol{\mu} \\
(\mathbf{e V})\end{array}$ & $\begin{array}{c}\mathbf{v}_{\mathbf{m}} \\
\left(\mathbf{s}^{-1}\right) \times \mathbf{1 0}^{-\mathbf{8}}\end{array}$ \\
\hline 1 & 24.39 & 1.65 & 1.52 & 1.07 \\
\hline 2 & 48.79 & 1.99 & 2.00 & 1.77 \\
\hline 4 & 97.57 & 2.41 & 232.59 & 2.91 \\
\hline 6 & 146.36 & 3.16 & 2662.51 & 3.34 \\
\hline 8 & 195.14 & 4.20 & 3089.33 & 3.35 \\
\hline 10 & 243.93 & 5.38 & 5483.32 & 3.27 \\
\hline
\end{tabular}

Table (3):-The calculated electron diffusion motion parameters in pure Helium gas

\begin{tabular}{|c|c|c|c|c|}
\hline $\begin{array}{c}\mathrm{E} / \mathrm{N} \\
\left(\mathrm{V} \cdot \mathrm{cm}_{17}^{2}\right) \times 10^{-}\end{array}$ & $\begin{array}{c}\mathbf{E} \\
(\mathrm{V} / \mathrm{cm})\end{array}$ & $\begin{array}{c}\text { W } \\
(\mathrm{cm} / \mathrm{s}) \times 10^{4}\end{array}$ & $\mathrm{D} / \mu(\mathrm{eV})$ & $\begin{array}{c}v_{\mathrm{m}} \\
\left(\mathrm{s}^{-1}\right) \times 10^{-7}\end{array}$ \\
\hline $1.20 \mathrm{E}-2$ & 3.05 & 2.70 & 0.03 & 7.98 \\
\hline $1.80 \mathrm{E}-2$ & 4.58 & 4.00 & 0.04 & 8.11 \\
\hline $4.60 \mathrm{E}-2$ & 11.44 & 8.80 & 0.04 & 9.13 \\
\hline $1.21 \mathrm{E}-1$ & 30.53 & 16.6 & 0.07 & $1.28 \mathrm{E}-1$ \\
\hline $1.82 \mathrm{E}-1$ & 45.77 & 20.7 & 0.1 & $1.54 \mathrm{E}-1$ \\
\hline $4.55 \mathrm{E}-1$ & 114.41 & 33.0 & 0.22 & $2.42 \mathrm{E}-1$ \\
\hline 1.21 & 305.27 & 53.4 & 0.52 & $4.00 \mathrm{E}-1$ \\
\hline 1.82 & 457.66 & 65.3 & 0.76 & $4.90 \mathrm{E}-1$ \\
\hline 2.43 & 611.05 & 75.7 & 1.01 & $5.64 \mathrm{E}-1$ \\
\hline 3.03 & 761.92 & 84.5 & 1.25 & $6.30 \mathrm{E}-1$ \\
\hline
\end{tabular}

Table (4):-The calculated electron diffusion motion parameters in mixture $\operatorname{Ar}(10 \%)-\mathrm{He}(45 \%)-\mathrm{N}_{2}(45 \%)$

\begin{tabular}{|c|c|c|c|c|}
\hline $\begin{array}{c}\mathrm{E} / \mathbf{N} \\
\left(\mathrm{V} . \mathrm{cm}_{15}^{2}\right) \times 10^{-}\end{array}$ & $\begin{array}{c}\mathbf{E} \\
(\mathrm{V} / \mathrm{cm})\end{array}$ & $\underset{(\mathrm{cm} / \mathrm{s}) \times 10^{5}}{\mathrm{~W}}$ & $\begin{array}{l}\mathrm{D} / \mu \\
(\mathrm{eV})\end{array}$ & $\left(\mathrm{s}^{-1}\right)_{8}^{v_{\mathrm{m}}} \times 10$ \\
\hline $9.98 \mathrm{E}-2$ & 6.426 & 1.32 & 0.087 & 1.33 \\
\hline $1.99 \mathrm{E}-1$ & 12.851 & 1.92 & 0.133 & 1.82 \\
\hline $3.99 \mathrm{E}-1$ & 25.703 & 2.89 & 0.199 & 2.43 \\
\hline $5.99 \mathrm{E}-1$ & 38.554 & 3.60 & 0.264 & 2.93 \\
\hline $7.99 \mathrm{E}-1$ & 51.406 & 4.18 & 0.327 & 3.36 \\
\hline $9.98 \mathrm{E}-1$ & 64.257 & 4.71 & 0.386 & 3.74 \\
\hline 1.997 & 128.514 & 7.06 & 0.597 & 4.98 \\
\hline 3.995 & 257.028 & 11.3 & 0.803 & 6.21 \\
\hline 5.993 & 385.542 & 15.4 & 0.903 & 6.85 \\
\hline 7.991 & 514.056 & 19.4 & 0.963 & 7.25 \\
\hline 9.989 & 642.57 & 23.3 & 1.003 & 7.55 \\
\hline
\end{tabular}


Table (5):-The calculated electron diffusion motion parameters in mixture $\operatorname{Ar}(90 \%)$ - $\mathrm{He}(5 \%)-\mathrm{N}_{2}(5 \%)$

\begin{tabular}{|c|c|c|c|c|}
\hline $\begin{array}{c}\mathbf{E} / \mathbf{N} \\
\left(\mathbf{V . c m}_{\mathbf{1 5}}^{\mathbf{2}}\right) \times \mathbf{1 0}\end{array}$ & $\begin{array}{c}\mathbf{E} \\
(\mathbf{V} / \mathbf{c m})\end{array}$ & $\begin{array}{c}\mathbf{W} \\
(\mathbf{c m} / \mathbf{s}) \\
\mathbf{\times 1 0}\end{array}$ & $\begin{array}{c}\mathbf{D} / \boldsymbol{\mu} \\
(\mathbf{e V})\end{array}$ & $\begin{array}{c}\mathbf{v}_{\mathbf{m}} \\
\left(\mathbf{s}^{-1}\right) \times \mathbf{1 0}^{-} \\
\mathbf{8}\end{array}$ \\
\hline 0.099 & 12.76 & 3.08 & 0.326 & 0.571 \\
\hline 0.199 & 25.52 & 3.68 & 0.551 & 0.956 \\
\hline 0.399 & 51.04 & 4.84 & 0.818 & 1.45 \\
\hline 0.599 & 76.56 & 6.05 & 0.966 & 1.74 \\
\hline 0.799 & 102.079 & 7.30 & 1.058 & 1.93 \\
\hline 0.9989 & 127.59 & 8.57 & 1.119 & 2.05 \\
\hline 1.997 & 255.198 & 15.0 & 1.255 & 2.34 \\
\hline 3.995 & 510.396 & 27.0 & 1.368 & 2.60 \\
\hline 5.99 & 765.594 & 37.9 & 1.438 & 2.78 \\
\hline 7.991 & 1020.79 & 49.1 & 1.47 & 2.86 \\
\hline 9.989 & 1275.99 & 61.0 & 1.484 & 2.88 \\
\hline
\end{tabular}

Table (6):-The calculated electron diffusion motion parameters in mixture $\operatorname{Ar}(95 \%)-\mathbf{H}_{2}(5 \%)$

\begin{tabular}{|c|c|c|c|c|}
\hline $\begin{array}{c}\mathrm{E} / \mathrm{N} \\
\left(\mathrm{V} \cdot \mathrm{cm}^{2}\right) \times 10^{-}\end{array}$ & $\begin{array}{c}E \\
(\mathrm{~V} / \mathrm{cm})\end{array}$ & $\begin{array}{c}\mathrm{W} \\
(\mathrm{cm} / \mathrm{s}) \\
\times 10^{4}\end{array}$ & $\begin{array}{l}\mathrm{D} / \mu \\
(\mathrm{eV})\end{array}$ & $\begin{array}{c}v_{\mathrm{m}} \\
\left(\mathrm{s}^{-1}\right) \times 10^{-8}\end{array}$ \\
\hline 0.0999 & 2.213 & 7.99 & 0.035 & 0.22 \\
\hline 0.20 & 4.426 & 17.0 & 0.059 & 0.207 \\
\hline 0.40 & 8.852 & 28.9 & 0.181 & 0.243 \\
\hline 0.599 & 13.279 & 34.6 & 0.173 & 0.305 \\
\hline 0.799 & 17.705 & 38.7 & 0.218 & 0.36 \\
\hline 0.999 & 22.131 & 42.5 & 0.253 & 0.414 \\
\hline 2.00 & 44.262 & 58.6 & 0.373 & 0.60 \\
\hline 4.00 & 88.524 & 79.4 & 0.537 & 0.886 \\
\hline 5.99 & 132.786 & 93.6 & 0.666 & 1.13 \\
\hline 7.99 & 177.048 & 105 & 0.775 & 1.34 \\
\hline 9.99 & 221.31 & 115 & 0.871 & 1.53 \\
\hline
\end{tabular}

Table (7):The calculated electron diffusion motion parameters in mixture $\operatorname{Ar}(5 \%)-\mathrm{H}_{2}(95 \%)$

\begin{tabular}{|c|c|c|c|c|}
\hline $\begin{array}{c}\mathbf{E} / \mathbf{N} \\
(\mathbf{V . c m}) \times \mathbf{1 0}^{-\mathbf{1 8}}\end{array}$ & $\begin{array}{c}\mathbf{E} \\
(\mathbf{V} / \mathbf{c m})\end{array}$ & $\begin{array}{c}\mathbf{W} \\
(\mathbf{c m} / \mathbf{s}) \times \mathbf{1 0}\end{array}$ & $\begin{array}{c}\mathbf{D} / \boldsymbol{\mu} \\
(\mathbf{e V})\end{array}$ & $\begin{array}{c}\mathbf{v}_{\mathbf{m}} \\
\left(\mathbf{s}^{\mathbf{1}}\right) \times \mathbf{1 0}^{-\mathbf{8}}\end{array}$ \\
\hline 0.099 & 0.232 & 1.46 & 0.03 & 1.20 \\
\hline 0.20 & 0.463 & 2.90 & 0.031 & 1.21 \\
\hline 0.40 & 0.926 & 5.60 & 0.033 & 1.26 \\
\hline 0.59 & 1.389 & 7.98 & 0.035 & 1.32 \\
\hline 0.799 & 1.852 & 10.0 & 0.038 & 1.40 \\
\hline 0.999 & 2.315 & 11.8 & 0.041 & 1.49 \\
\hline 2.00 & 4.63 & 18.4 & 0.059 & 1.91 \\
\hline 4.00 & 9.26 & 26.5 & 0.095 & 2.65 \\
\hline 5.99 & 13.89 & 32.3 & 0.127 & 3.27 \\
\hline 7.99 & 18.52 & 37.1 & 0.157 & 3.79 \\
\hline 9.99 & 23.15 & 41.5 & 0.183 & 4.24 \\
\hline
\end{tabular}

Table(8):-The calculated transport coefficient parameters for pure Nitrogen gas

\begin{tabular}{|c|c|c|c|}
\hline $\begin{array}{c}\mathbf{E} / \mathbf{N} \\
\left(\mathbf{V} \cdot \mathbf{c m}^{\mathbf{2}}\right)\end{array}$ & $\begin{array}{c}\mathbf{E} / \mathbf{P} \\
\left(\mathbf{V ~ c m}^{-1} \mathbf{T o r r}^{-\mathbf{1}}\right)\end{array}$ & $\mathbf{W}_{\mathbf{M}}$ & $\boldsymbol{\psi}$ \\
\hline $5.00 \mathrm{E}-17$ & $1.61 \mathrm{E}+00$ & $2.91 \mathrm{E}+18$ & $2.67 \mathrm{E}+12$ \\
\hline $1.00 \mathrm{E}-16$ & $3.22 \mathrm{E}+00$ & $4.76 \mathrm{E}+18$ & $2.67 \mathrm{E}+12$ \\
\hline $2.00 \mathrm{E}-16$ & $6.45 \mathrm{E}+00$ & $8.18 \mathrm{E}+18$ & $2.67 \mathrm{E}+12$ \\
\hline $3.00 \mathrm{E}-16$ & $9.67 \mathrm{E}+00$ & $1.12 \mathrm{E}+19$ & $2.67 \mathrm{E}+12$ \\
\hline $4.00 \mathrm{E}-16$ & $1.29 \mathrm{E}+01$ & $1.36 \mathrm{E}+19$ & $2.68 \mathrm{E}+12$ \\
\hline $5.00 \mathrm{E}-16$ & $1.61 \mathrm{E}+01$ & $1.54 \mathrm{E}+19$ & $2.67 \mathrm{E}+12$ \\
\hline
\end{tabular}

Table(9):-The calculated transport coefficient parameters for pure Argon gas

\begin{tabular}{|c|c|c|c|}
\hline $\begin{array}{c}\mathbf{E} / \mathbf{N} \\
\left(\mathbf{V} . \mathbf{c m}^{\mathbf{2}}\right)\end{array}$ & $\begin{array}{c}\mathbf{E} / \mathbf{P} \\
\left(\mathbf{V ~ c m}^{-\mathbf{1}} \mathbf{T o r r}^{-1}\right)\end{array}$ & $\mathbf{W}_{\mathbf{M}}$ & $\boldsymbol{\Psi}$ \\
\hline $1.00 \mathrm{E}-18$ & $3.22 \mathrm{E}-02$ & $4.01 \mathrm{E}+17$ & $2.43 \mathrm{E}+12$ \\
\hline $2.00 \mathrm{E}-18$ & $6.45 \mathrm{E}-02$ & $4.85 \mathrm{E}+17$ & $2.44 \mathrm{E}+12$ \\
\hline $4.00 \mathrm{E}-18$ & $1.29 \mathrm{E}-01$ & $5.90 \mathrm{E}+17$ & $2.45 \mathrm{E}+12$ \\
\hline $6.00 \mathrm{E}-18$ & $1.93 \mathrm{E}-01$ & $7.71 \mathrm{E}+17$ & $2.44 \mathrm{E}+12$ \\
\hline $8.00 \mathrm{E}-18$ & $2.58 \mathrm{E}-01$ & $1.03 \mathrm{E}+18$ & $2.44 \mathrm{E}+12$ \\
\hline $1.00 \mathrm{E}-17$ & $3.22 \mathrm{E}-01$ & $1.31 \mathrm{E}+18$ & $2.44 \mathrm{E}+12$ \\
\hline
\end{tabular}

Table(10) :-The calculated transport coefficient parameters for pure Helium gas

\begin{tabular}{|c|c|c|c|}
\hline $\begin{array}{c}\mathbf{E} / \mathbf{N} \\
\left(\mathbf{V} . \mathbf{c m}^{2}\right)\end{array}$ & $\begin{array}{c}\mathbf{E} / \mathbf{P} \\
\left(\mathbf{V ~ c m}^{-1} \mathbf{T o r r}^{-1}\right)\end{array}$ & $\mathbf{W}_{\mathbf{M}}$ & $\boldsymbol{\Psi}$ \\
\hline $1.20 \mathrm{E}-19$ & $3.87 \mathrm{E}-03$ & $6.73 \mathrm{E}+14$ & $2.49 \mathrm{E}+10$ \\
\hline $1.80 \mathrm{E}-19$ & $5.80 \mathrm{E}-03$ & $9.94 \mathrm{E}+14$ & $2.49 \mathrm{E}+10$ \\
\hline $4.60 \mathrm{E}-19$ & $1.48 \mathrm{E}-02$ & $2.20 \mathrm{E}+15$ & $2.50 \mathrm{E}+10$ \\
\hline $1.21 \mathrm{E}-18$ & $3.90 \mathrm{E}-02$ & $4.20 \mathrm{E}+17$ & $2.53 \mathrm{E}+12$ \\
\hline $1.82 \mathrm{E}-18$ & $5.87 \mathrm{E}-02$ & $5.23 \mathrm{E}+17$ & $2.53 \mathrm{E}+12$ \\
\hline $4.55 \mathrm{E}-18$ & $1.47 \mathrm{E}-01$ & $8.32 \mathrm{E}+17$ & $2.52 \mathrm{E}+12$ \\
\hline $1.21 \mathrm{E}-17$ & $3.91 \mathrm{E}-01$ & $1.34 \mathrm{E}+18$ & $2.52 \mathrm{E}+12$ \\
\hline $1.82 \mathrm{E}-17$ & $5.87 \mathrm{E}-01$ & $1.64 \mathrm{E}+18$ & $2.52 \mathrm{E}+12$ \\
\hline $2.43 \mathrm{E}-17$ & $7.83 \mathrm{E}-01$ & $1.91 \mathrm{E}+18$ & $2.52 \mathrm{E}+12$ \\
\hline $3.03 \mathrm{E}-17$ & $9.77 \mathrm{E}-01$ & $2.13 \mathrm{E}+18$ & $2.52 \mathrm{E}+12$ \\
\hline
\end{tabular}

Table(11):- The calculated transport coefficient parameters in mixture Ar(10\%) - $\mathbf{H e}(\mathbf{4 5} \%)-\mathbf{N}_{\mathbf{2}}(\mathbf{4 5} \%)$
\begin{tabular}{|c|c|c|c|}
\hline $\begin{array}{c}\mathbf{E} / \mathbf{N} \\
(\mathbf{V . c m})\end{array}$ & $\begin{array}{c}\mathbf{E} / \mathbf{P} \\
\left(\mathbf{V ~ c m}^{-1} \mathbf{T o r r}^{-1}\right)\end{array}$ & $\mathbf{W}_{\mathbf{M}}$ & $\boldsymbol{\Psi}$ \\
\hline $9.99 \mathrm{E}-17$ & 3.22 & $8.52 \mathrm{E}+16$ & $6.44 \mathrm{E}+11$ \\
\hline $1.99 \mathrm{E}-16$ & 6.44 & $1.24 \mathrm{E}+17$ & $6.46 \mathrm{E}+11$ \\
\hline $3.99 \mathrm{E}-16$ & 12.88 & $1.86 \mathrm{E}+17$ & $6.43 \mathrm{E}+11$ \\
\hline $5.99 \mathrm{E}-16$ & 19.32 & $2.32 \mathrm{E}+17$ & $6.44 \mathrm{E}+11$ \\
\hline $7.99 \mathrm{E}-16$ & 25.76 & $2.69 \mathrm{E}+17$ & $6.43 \mathrm{E}+11$ \\
\hline $9.98 \mathrm{E}-16$ & 32.2 & $3.03 \mathrm{E}+17$ & $6.43 \mathrm{E}+11$ \\
\hline $1.99 \mathrm{E}-15$ & 64.4 & $4.54 \mathrm{E}+17$ & $6.43 \mathrm{E}+11$ \\
\hline $3.99 \mathrm{E}-15$ & 128.8 & $7.28 \mathrm{E}+17$ & $6.43 \mathrm{E}+11$ \\
\hline $5.99 \mathrm{E}-15$ & 193.2 & $9.90 \mathrm{E}+17$ & $6.43 \mathrm{E}+11$ \\
\hline $7.99 \mathrm{E}-15$ & 257.6 & $1.25 \mathrm{E}+18$ & $6.43 \mathrm{E}+11$ \\
\hline $9.98 \mathrm{E}-15$ & 322 & $1.50 \mathrm{E}+18$ & $6.43 \mathrm{E}+11$ \\
\hline
\end{tabular}

Table(12) :-The calculated transport coefficient parameters in mixture $\operatorname{Ar}(50 \%)-\mathrm{He}(25 \%)-\mathrm{N}_{2}(25 \%)$

\begin{tabular}{|c|c|c|c|}
\hline $\begin{array}{c}\mathbf{E} / \mathbf{N} \\
(\mathbf{V . c m}\end{array}$ & $\begin{array}{c}\mathbf{E} / \mathbf{P} \\
\left(\mathbf{V ~ c m}^{-1} \mathbf{T o r r}^{-1}\right)\end{array}$ & $\mathbf{W}_{\mathbf{M}}$ & $\boldsymbol{\psi}$ \\
\hline $9.98 \mathrm{E}-17$ & 3.22 & $1.69 \mathrm{E}+17$ & $9.54 \mathrm{E}+11$ \\
\hline $1.99 \mathrm{E}-16$ & 6.44 & $2.53 \mathrm{E}+17$ & $9.54 \mathrm{E}+11$ \\
\hline $3.99 \mathrm{E}-16$ & 12.88 & $3.59 \mathrm{E}+17$ & $9.54 \mathrm{E}+11$ \\
\hline $5.99 \mathrm{E}-16$ & 19.32 & $4.36 \mathrm{E}+17$ & $9.56 \mathrm{E}+11$ \\
\hline $7.99 \mathrm{E}-16$ & 25.76 & $5.02 \mathrm{E}+17$ & $9.54 \mathrm{E}+11$ \\
\hline $9.98 \mathrm{E}-16$ & 32.2 & $5.67 \mathrm{E}+17$ & $9.54 \mathrm{E}+11$ \\
\hline $1.99 \mathrm{E}-15$ & 64.4 & $8.76 \mathrm{E}+17$ & $9.54 \mathrm{E}+11$ \\
\hline $3.99 \mathrm{E}-15$ & 128.8 & $1.47 \mathrm{E}+18$ & $9.54 \mathrm{E}+11$ \\
\hline $5.99 \mathrm{E}-15$ & 193.2 & $2.04 \mathrm{E}+18$ & $9.54 \mathrm{E}+11$ \\
\hline $7.99 \mathrm{E}-15$ & 257.6 & $2.60 \mathrm{E}+18$ & $9.54 \mathrm{E}+11$ \\
\hline $9.98 \mathrm{E}-15$ & 322 & $3.12 \mathrm{E}+18$ & $9.54 \mathrm{E}+11$ \\
\hline
\end{tabular}


Table(13) :-The calculated transport coefficient parameters in mixture $\operatorname{Ar}(90 \%)-\mathrm{He}(5 \%)-\mathrm{N}_{2}(5 \%)$

\begin{tabular}{|c|c|c|c|}
\hline $\begin{array}{c}\mathbf{E} / \mathbf{N} \\
\left(\mathbf{V} \mathbf{c m}^{\mathbf{2}}\right)\end{array}$ & $\begin{array}{c}\mathbf{E} / \mathbf{P} \\
\left(\mathbf{V} \mathbf{~ c m}^{-1} \mathbf{T o r r}^{-\mathbf{1}}\right)\end{array}$ & $\mathbf{W}_{\mathbf{M}}$ & $\boldsymbol{\Psi}$ \\
\hline $9.98966 \mathrm{E}-17$ & 3.22 & $3.93 \mathrm{E}+17$ & $1.28 \mathrm{E}+12$ \\
\hline $1.99793 \mathrm{E}-16$ & 6.44 & $4.70 \mathrm{E}+17$ & $1.28 \mathrm{E}+12$ \\
\hline $3.99586 \mathrm{E}-16$ & 12.88 & $6.18 \mathrm{E}+17$ & $1.28 \mathrm{E}+12$ \\
\hline $5.9938 \mathrm{E}-16$ & 19.32 & $7.73 \mathrm{E}+17$ & $1.28 \mathrm{E}+12$ \\
\hline $7.99173 \mathrm{E}-16$ & 25.76 & $9.32 \mathrm{E}+17$ & $1.28 \mathrm{E}+12$ \\
\hline $9.98966 \mathrm{E}-16$ & 32.2 & $1.09 \mathrm{E}+18$ & $1.28 \mathrm{E}+12$ \\
\hline $1.99793 \mathrm{E}-15$ & 64.4 & $1.92 \mathrm{E}+18$ & $1.28 \mathrm{E}+12$ \\
\hline $3.99586 \mathrm{E}-15$ & 128.8 & $3.45 \mathrm{E}+18$ & $1.28 \mathrm{E}+12$ \\
\hline $5.9938 \mathrm{E}-15$ & 193.2 & $4.85 \mathrm{E}+18$ & $1.28 \mathrm{E}+12$ \\
\hline $7.99173 \mathrm{E}-15$ & 257.6 & $6.28 \mathrm{E}+18$ & $1.28 \mathrm{E}+12$ \\
\hline $9.98966 \mathrm{E}-15$ & 322 & $7.79 \mathrm{E}+18$ & $1.28 \mathrm{E}+12$ \\
\hline
\end{tabular}

Table(14): The calculated transport coefficient parameters in mixture $\operatorname{Ar}(\mathbf{9 5 \%})-\mathbf{H}_{2}(5 \%)$

\begin{tabular}{|c|c|c|c|}
\hline $\begin{array}{c}\mathbf{E} / \mathbf{N} \\
\left(\mathbf{V} \mathbf{c m}^{\mathbf{2}}\right)\end{array}$ & $\begin{array}{c}\mathbf{E} / \mathbf{P} \\
\left(\mathbf{V ~ c m}^{-1} \mathbf{T o r r}^{-1}\right)\end{array}$ & $\mathbf{W}_{\mathbf{M}}$ & $\boldsymbol{\Psi}$ \\
\hline $9.99 \mathrm{E}-20$ & $3.22 \mathrm{E}-03$ & $1.77 \mathrm{E}+17$ & $2.22 \mathrm{E}+12$ \\
\hline $2.00 \mathrm{E}-19$ & $6.44 \mathrm{E}-03$ & $3.76 \mathrm{E}+17$ & $2.22 \mathrm{E}+12$ \\
\hline $4.00 \mathrm{E}-19$ & $1.29 \mathrm{E}-02$ & $6.41 \mathrm{E}+17$ & $2.22 \mathrm{E}+12$ \\
\hline $5.99 \mathrm{E}-19$ & $1.93 \mathrm{E}-02$ & $7.66 \mathrm{E}+17$ & $2.22 \mathrm{E}+12$ \\
\hline $7.99 \mathrm{E}-19$ & $2.58 \mathrm{E}-02$ & $8.56 \mathrm{E}+17$ & $2.21 \mathrm{E}+12$ \\
\hline $9.99 \mathrm{E}-19$ & $3.22 \mathrm{E}-02$ & $9.41 \mathrm{E}+17$ & $2.21 \mathrm{E}+12$ \\
\hline $2.00 \mathrm{E}-18$ & $6.44 \mathrm{E}-02$ & $1.30 \mathrm{E}+18$ & $2.22 \mathrm{E}+12$ \\
\hline $4.00 \mathrm{E}-18$ & $1.29 \mathrm{E}-01$ & $1.76 \mathrm{E}+18$ & $2.22 \mathrm{E}+12$ \\
\hline $5.99 \mathrm{E}-18$ & $1.93 \mathrm{E}-01$ & $2.07 \mathrm{E}+18$ & $2.22 \mathrm{E}+12$ \\
\hline $7.99 \mathrm{E}-18$ & $2.58 \mathrm{E}-01$ & $2.32 \mathrm{E}+18$ & $2.22 \mathrm{E}+12$ \\
\hline $9.99 \mathrm{E}-18$ & $3.22 \mathrm{E}-01$ & $2.54 \mathrm{E}+18$ & $2.21 \mathrm{E}+12$ \\
\hline
\end{tabular}

Table(15):-The calculated transport coefficient parameters in mixture $\left.\operatorname{Ar}(45 \%)-\mathbf{H}_{2} 55 \%\right)$

\begin{tabular}{|c|c|c|c|}
\hline $\begin{array}{c}\mathbf{E} / \mathbf{N} \\
\left(\mathbf{V} \mathbf{c m}^{2}\right)\end{array}$ & $\begin{array}{c}\mathbf{E} / \mathbf{P} \\
\left(\mathbf{V ~ c m}^{-1} \mathbf{T o r r}^{-1}\right)\end{array}$ & $\mathbf{W}_{\mathbf{M}}$ & $\Psi$ \\
\hline $9.99 \mathrm{E}-20$ & $3.22 \mathrm{E}-03$ & $2.83 \mathrm{E}+16$ & $1.11 \mathrm{E}+12$ \\
\hline $2.00 \mathrm{E}-19$ & $6.44 \mathrm{E}-03$ & $5.53 \mathrm{E}+16$ & $1.11 \mathrm{E}+12$ \\
\hline $4.00 \mathrm{E}-19$ & $1.29 \mathrm{E}-02$ & $1.02 \mathrm{E}+17$ & $1.11 \mathrm{E}+12$ \\
\hline $5.99 \mathrm{E}-19$ & $1.93 \mathrm{E}-02$ & $1.40 \mathrm{E}+17$ & $1.11 \mathrm{E}+12$ \\
\hline $7.99 \mathrm{E}-19$ & $2.58 \mathrm{E}-02$ & $1.72 \mathrm{E}+17$ & $1.11 \mathrm{E}+12$ \\
\hline $9.99 \mathrm{E}-19$ & $3.22 \mathrm{E}-02$ & $1.99 \mathrm{E}+17$ & $1.11 \mathrm{E}+12$ \\
\hline $2.00 \mathrm{E}-18$ & $6.44 \mathrm{E}-02$ & $2.96 \mathrm{E}+17$ & $1.11 \mathrm{E}+12$ \\
\hline $4.00 \mathrm{E}-18$ & $1.29 \mathrm{E}-01$ & $4.17 \mathrm{E}+17$ & $1.11 \mathrm{E}+12$ \\
\hline $5.99 \mathrm{E}-18$ & $1.93 \mathrm{E}-01$ & $5.14 \mathrm{E}+17$ & $1.11 \mathrm{E}+12$ \\
\hline $7.99 \mathrm{E}-18$ & $2.58 \mathrm{E}-01$ & $6.09 \mathrm{E}+17$ & $1.11 \mathrm{E}+12$ \\
\hline $9.99 \mathrm{E}-18$ & $3.22 \mathrm{E}-01$ & $6.98 \mathrm{E}+17$ & $1.11 \mathrm{E}+12$ \\
\hline
\end{tabular}

Table(16):-The calculated transport coefficient parameters in mixture $\operatorname{Ar}(5 \%)-\mathbf{H}_{2}(\mathbf{9 5} \%)$

\begin{tabular}{|c|c|c|c|}
\hline $\begin{array}{c}\mathbf{E} / \mathbf{N} \\
\left(\mathbf{V} . \mathbf{c m}^{\mathbf{2}}\right)\end{array}$ & $\begin{array}{c}\mathbf{E} / \mathbf{P} \\
\left(\mathbf{V ~ c m}^{-1} \text { Torr }^{-1}\right)\end{array}$ & $\mathbf{W}_{\mathbf{M}}$ & $\boldsymbol{\Psi}$ \\
\hline $9.99 \mathrm{E}-20$ & $3.22 \mathrm{E}-03$ & $3.40 \mathrm{E}+15$ & $2.33 \mathrm{E}+11$ \\
\hline $2.00 \mathrm{E}-19$ & $6.44 \mathrm{E}-03$ & $6.72 \mathrm{E}+15$ & $2.32 \mathrm{E}+11$ \\
\hline $4.00 \mathrm{E}-19$ & $1.29 \mathrm{E}-02$ & $1.30 \mathrm{E}+16$ & $2.32 \mathrm{E}+11$ \\
\hline $5.99 \mathrm{E}-19$ & $1.93 \mathrm{E}-02$ & $1.85 \mathrm{E}+16$ & $2.32 \mathrm{E}+11$ \\
\hline $7.99 \mathrm{E}-19$ & $2.58 \mathrm{E}-02$ & $2.33 \mathrm{E}+16$ & $2.32 \mathrm{E}+11$ \\
\hline $9.99 \mathrm{E}-19$ & $3.22 \mathrm{E}-02$ & $2.74 \mathrm{E}+16$ & $2.31 \mathrm{E}+11$ \\
\hline $2.00 \mathrm{E}-18$ & $6.44 \mathrm{E}-02$ & $4.26 \mathrm{E}+16$ & $2.32 \mathrm{E}+11$ \\
\hline $4.00 \mathrm{E}-18$ & $1.29 \mathrm{E}-01$ & $6.15 \mathrm{E}+16$ & $2.32 \mathrm{E}+11$ \\
\hline $5.99 \mathrm{E}-18$ & $1.93 \mathrm{E}-01$ & $7.48 \mathrm{E}+16$ & $2.32 \mathrm{E}+11$ \\
\hline $7.99 \mathrm{E}-18$ & $2.58 \mathrm{E}-01$ & $8.59 \mathrm{E}+16$ & $2.32 \mathrm{E}+11$ \\
\hline $9.99 \mathrm{E}-18$ & $3.22 \mathrm{E}-01$ & $9.62 \mathrm{E}+16$ & $2.32 \mathrm{E}+11$ \\
\hline
\end{tabular}

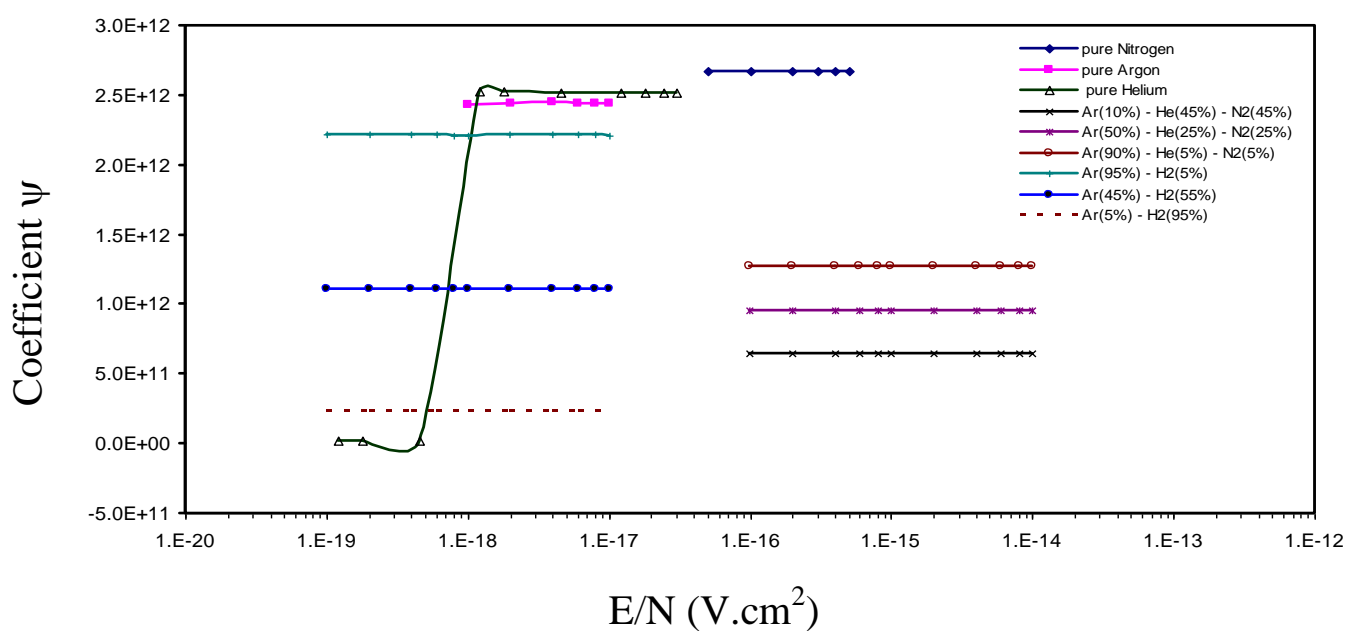

Fig.(1): The magnetic deflection coefficient versus the ratio of the applied electric field to the gas total number density in a pure nitrogen, Argon, Helium, Ar-He- $\mathrm{N}_{2}$ mixture and $\mathrm{Ar}-\mathrm{H}_{2}$ mixture. 


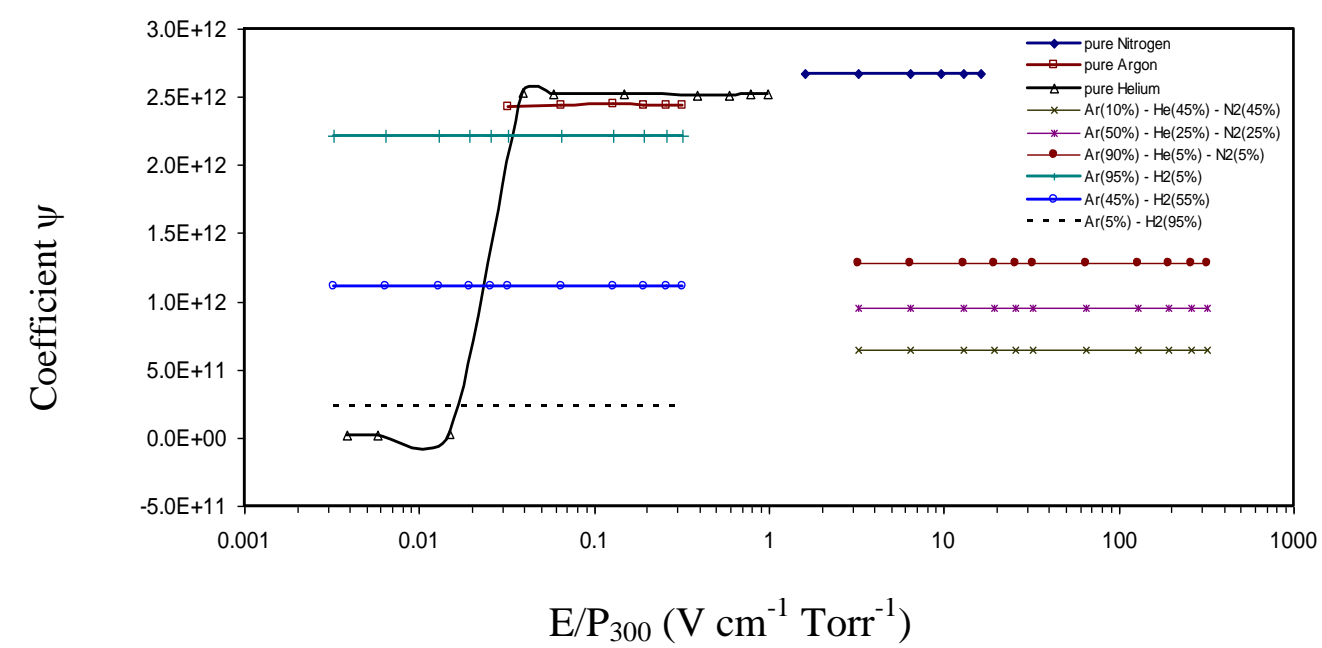

Fig.(2): The magnetic deflection coefficient versus the ratio of the applied electric field to the gas pressure in a pure nitrogen, Argon, Helium, Ar-He$\mathrm{N}_{2}$ mixture and Ar- $\mathrm{H}_{2}$ mixture.

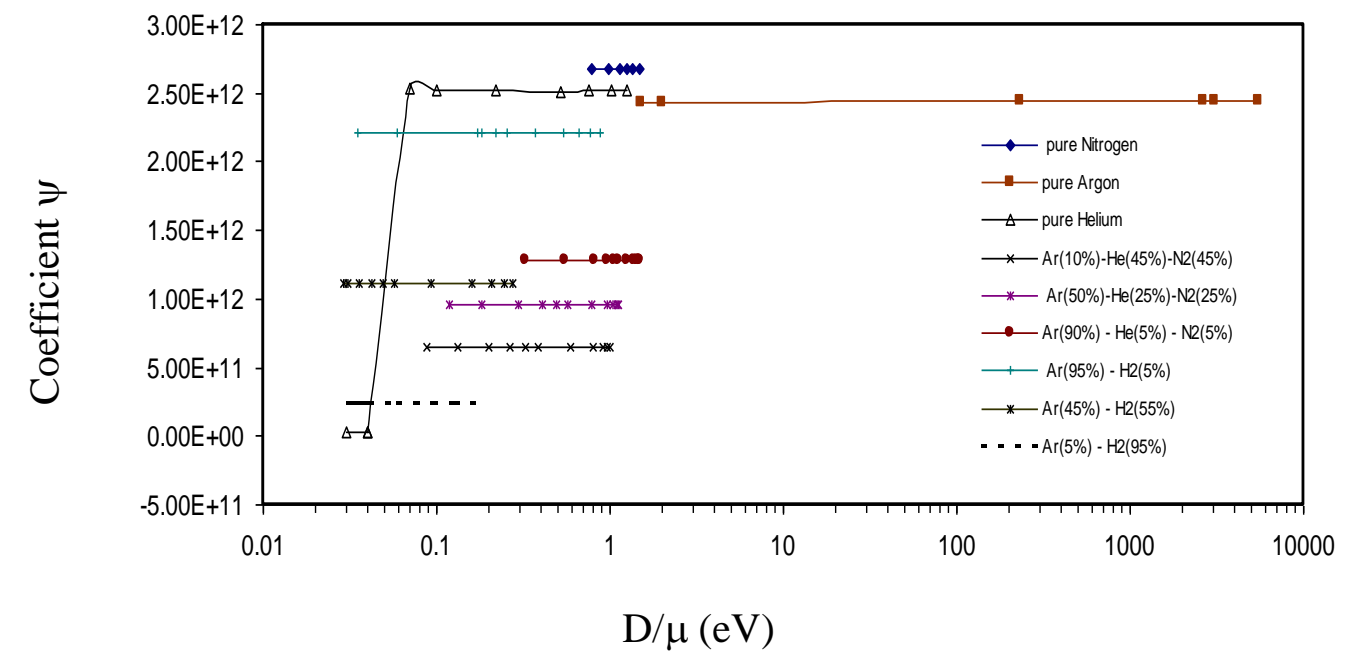

Fig.(3): The magnetic deflection coefficient versus the ratio of the applied electric field to the diffusion coefficient to the electron mobility ratio in a pure nitrogen, Argon, Helium, Ar-He- $\mathrm{N}_{2}$ mixture and $\mathrm{Ar}-\mathrm{H}_{2}$ mixture.

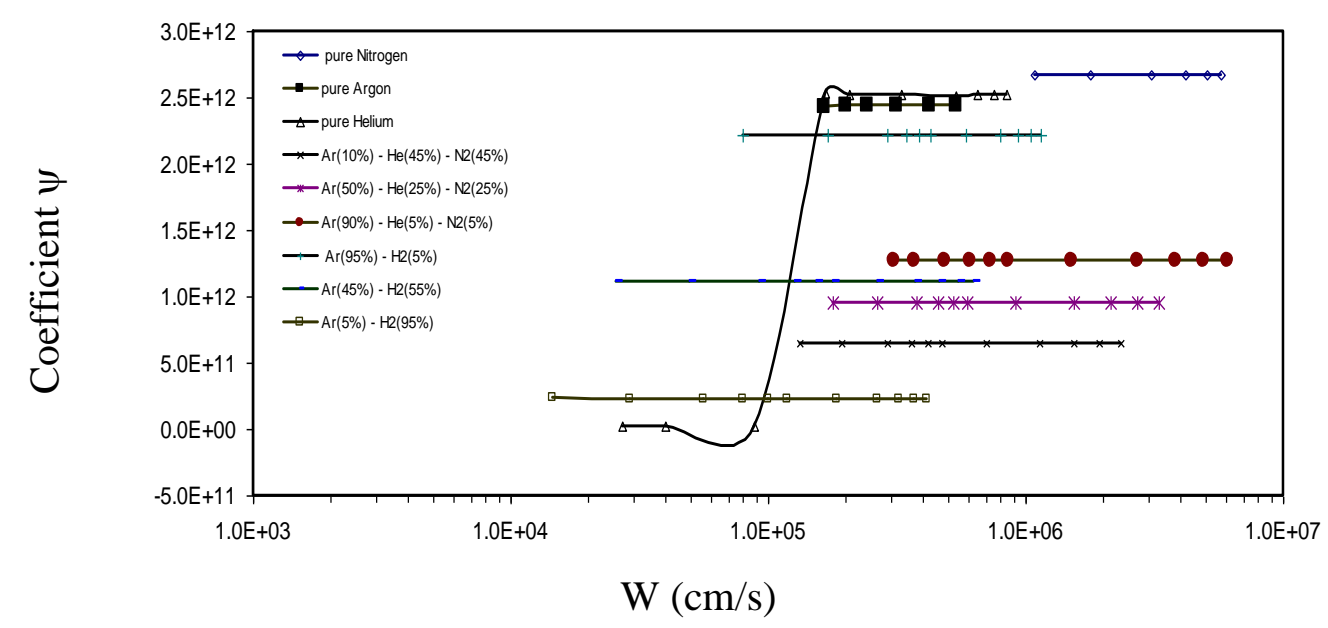

Fig.(4): The magnetic deflection coefficient versus the ratio of the applied electric field to the drift velocity in a pure nitrogen, Argon, Helium, Ar$\mathrm{He}-\mathrm{N}_{2}$ mixture and $\mathrm{Ar}-\mathrm{H}_{2}$ mixture. 


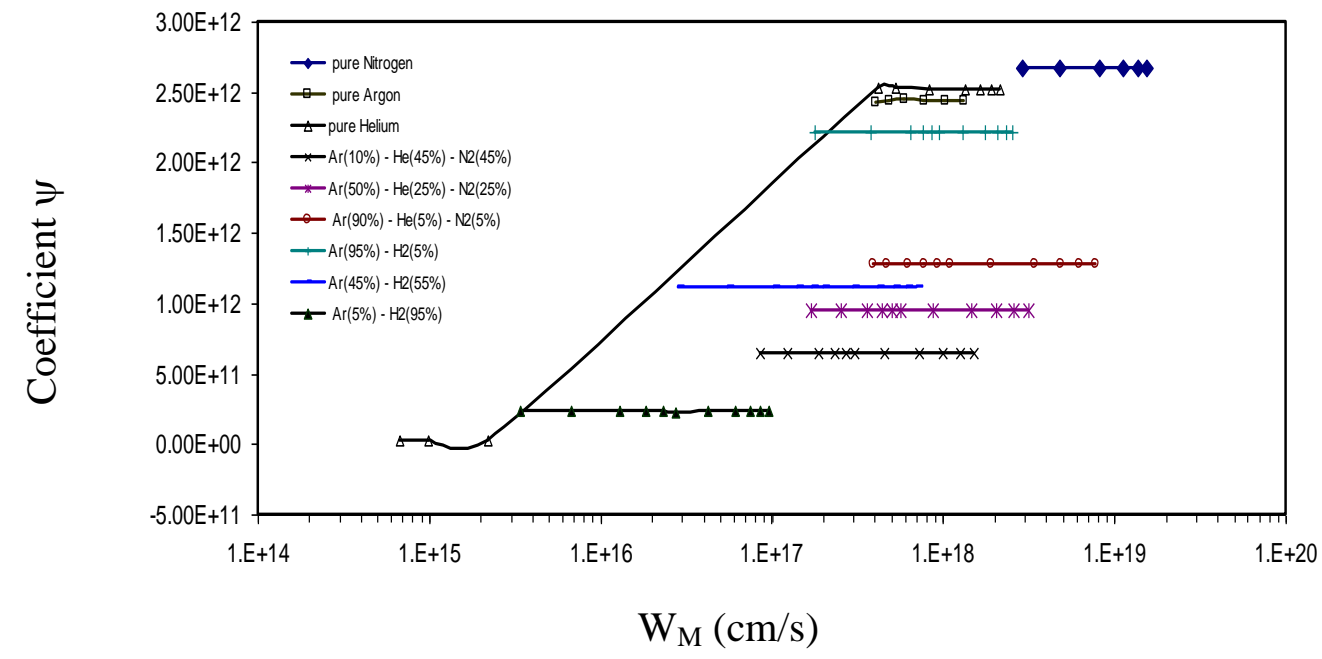

Fig.(5): The magnetic deflection coefficient versus to the magnetic drift velocity in a pure nitrogen, Argon, Helium, Ar-He- $\mathrm{N}_{2}$ mixture and $\mathrm{Ar}-\mathrm{H}_{2}$ mixture.

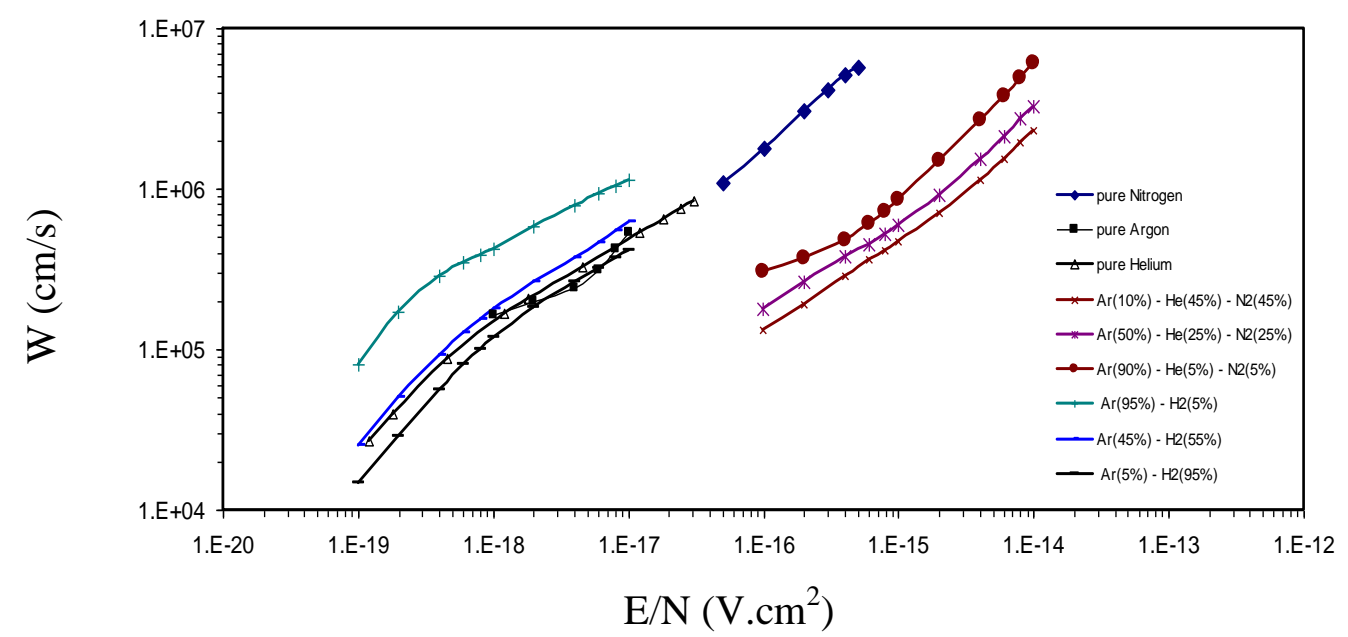

Fig.(6): The drift velocity versus the ratio of the applied electric field to the gas total number density in a pure nitrogen, Argon, Helium, Ar-He- $\mathrm{N}_{2}$ mixture and Ar-H mixture.

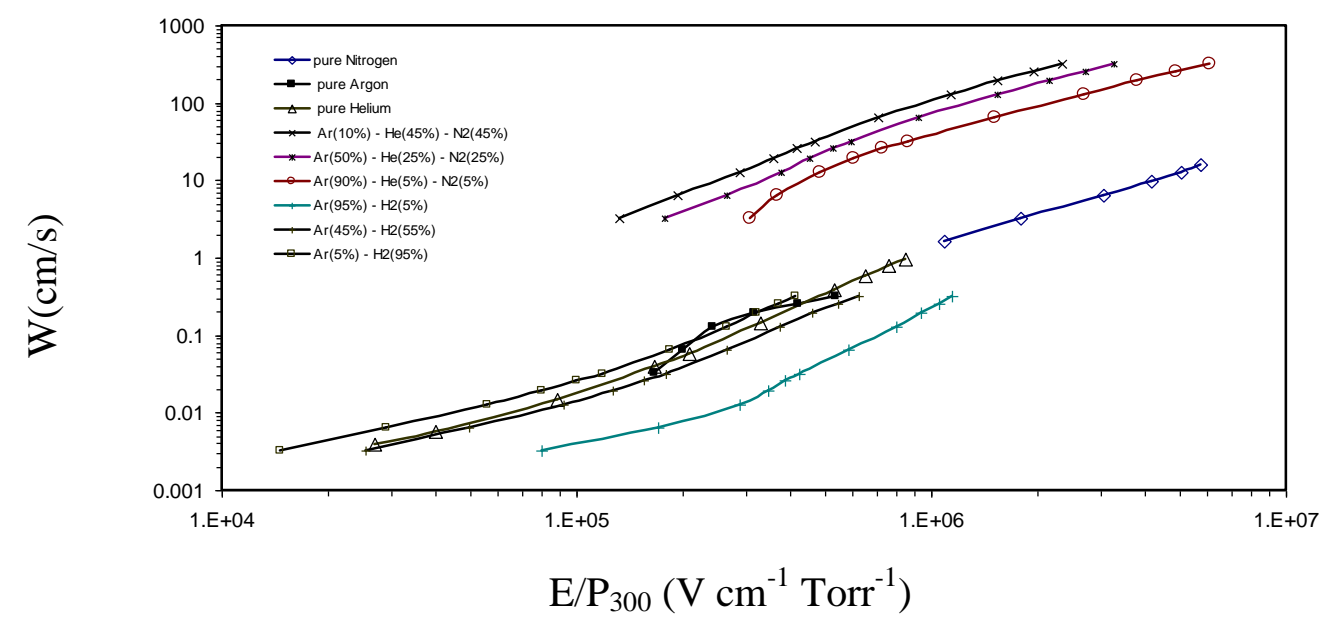

Fig.(7): The drift velocity versus the ratio of the applied electric field to the gas pressure in a pure nitrogen, Argon, Helium and Ar-He- $\mathrm{N}_{2}$ mixture and Ar- $\mathrm{H}_{2}$ mixture. 


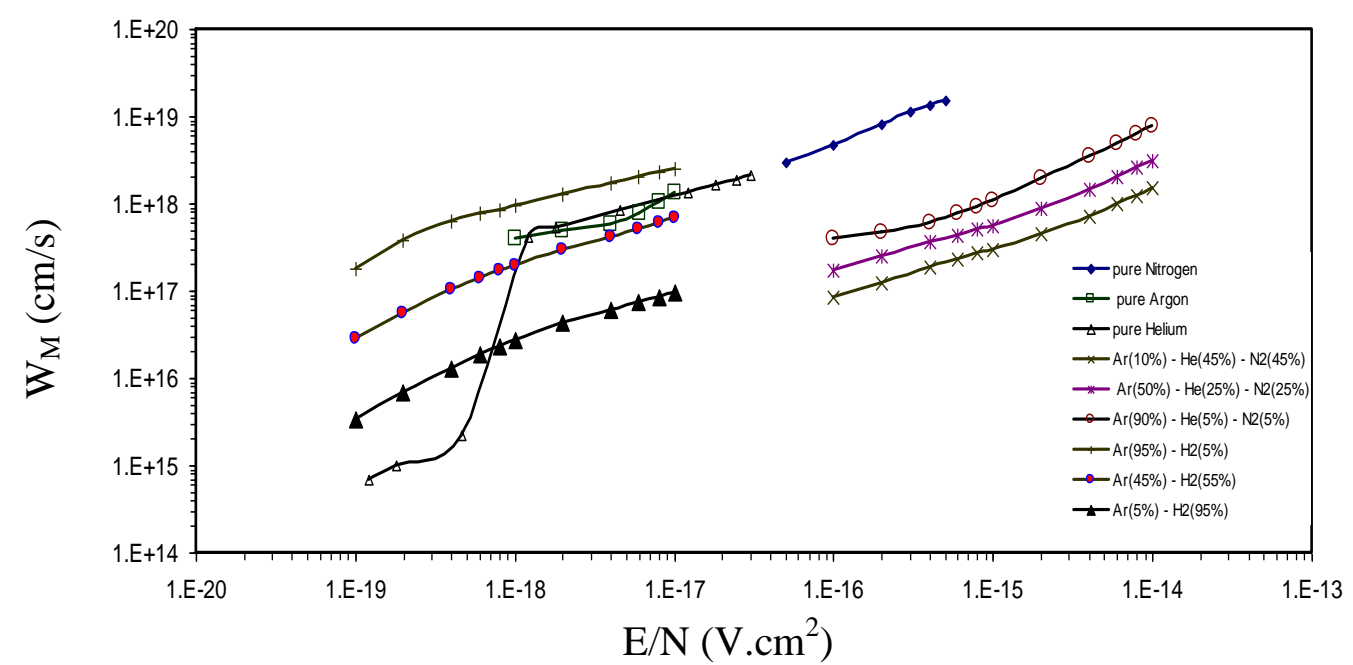

Fig.(8): The magnetic drift velocity versus the ratio of the applied electric field to the gas total number density in a pure nitrogen, Argon, Helium, and Ar-He- $\mathrm{N}_{2}$ mixture and $\mathrm{Ar}-\mathrm{H}_{2}$ mixture.

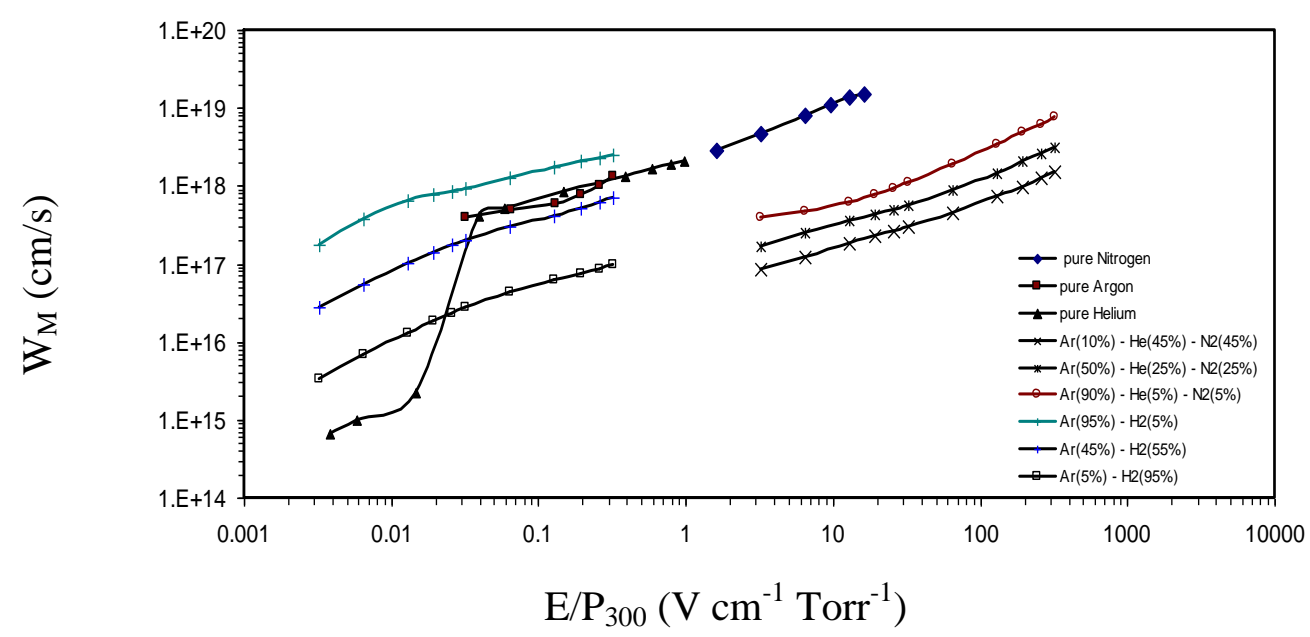

Fig.(9): The magnetic drift velocity versus the ratio of the applied electric field to the gas pressure in a pure Nitrogen, Argon, Helium and Ar-He- $\mathrm{N}_{2}$ mixture and $\mathrm{Ar}-\mathrm{H}_{2}$ mixture.

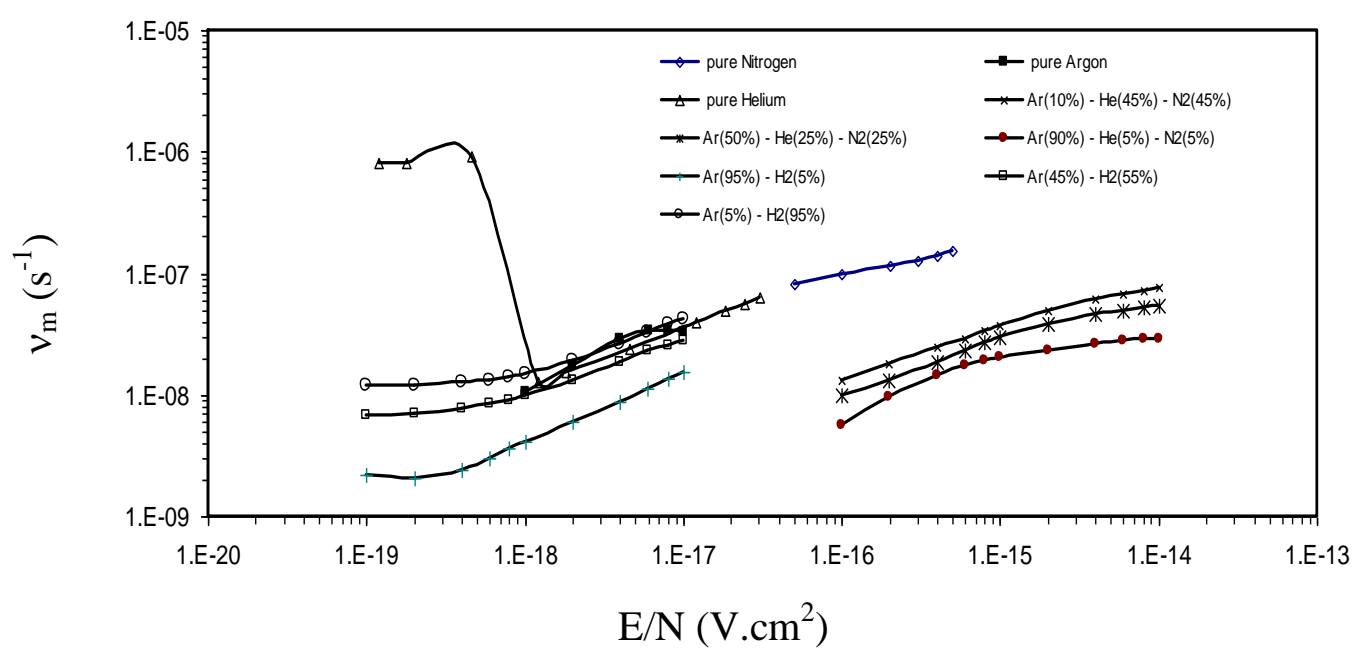

Fig.(10): The momentum transfer collision frequency versus the ratio of the applied electric field to the gas total number density in a pure Nitrogen, Argon, Helium and Ar-He- $\mathrm{N}_{2}$ mixture and $\mathrm{Ar}-\mathrm{H}_{2}$ mixture. 


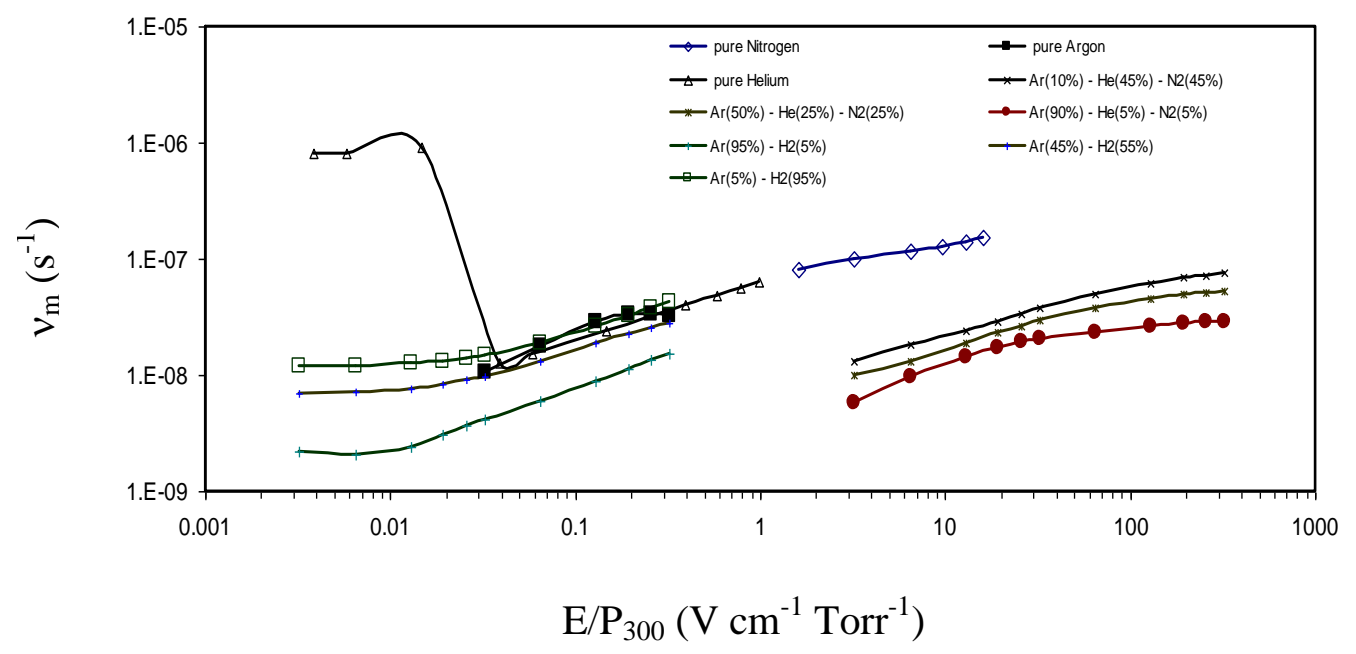

Fig.(11): The momentum transfer collision frequency versus the ratio of the applied electric field to the gas pressure in a pure Nitrogen, Argon, Helium and Ar-He- $\mathrm{N}_{2}$ mixture and $\mathrm{Ar}-\mathrm{H}_{2}$ mixture.

\section{References:}

1. Creaser R. P., 1967, Measurement of the Magnetic Drift Velocity and Magnetic Deflection Coefficient for Slow Electrons in Hydrogen and Deuterium at $293^{\circ} \mathrm{k}$, Aust. J. Phys. 20, 547-555.

2. Boris M. Smirnov, Physics of Ionized Gases, John Wiley \& Sons, Inc. New York, 2001.

3. Farhan Lafta Rasheed, Ibrahem Gittan Faiadh and Hameed Balassim Mahood 2005. Calculation of the Characteristic Electron Energy for MercuryArgon Mixture $\mathrm{J} \mathrm{Um}^{\circ}$-Salama for science, 2, (3): 477.

4. Serway, Raymond A., Jewett, John W.2004, Physics for Scientists and Engineers ( $6^{\text {th }}$ ed.) Brooks/cde.

5. Jory R. L. 1965, Transport Coefficients for Low Energy Electrons in Crossed Elictric and Magnetic Fields, Aust. J. Phys. 18, 237-256.

6. Loureiro J. and Ferreira C. M., 1989. Electron Excitation Rates and Transport Parameters in Direct-Current $\mathrm{N}_{2}$ Discharges, J. phys. D: Appl. Phys., 22,67-75.
7. Ostrikov k., Denysenko M. Y. Yu. And S. Xu.,2005, Electron Energy Distribution Function in LowPressure Complex Plasmas, J. Plasma Physics, (Cambridge University press), 71, (2): 217-224.

8. Stephen, Rockwood D. 1973, Elastic and Inelastic Cross Section for Electron-HG Scattering from HG Transport Data, Phys. Rev., A. 85, (23): 48-58.

9. Rockwood S. D. and Greene A. E. 1980, Numerical Solutions of Boltzmann Transport Equation, Computer Physics Communications 19: 377-393.

10. Crompton R. W., Elford M. T. and Jory R. L. 1967, The momentum Transfer Cross Section for Electrons in Helium, Aust. J. Phys., 20: 369.

11. Frost L. S. and Phelps A. V. 1962, Rotational Excitation and Momentum Transfer cross Sections for Electrons in $\mathrm{H}_{2} \& \mathrm{~N}_{2}$ from Transport Coefficients, Phys. Rev. 127, (5): 1621-1633. 
تحقيق معامل الانحراف المغتاطيسي للجسيمات الواطئة الطاقة

فيصل غازي حمودي*

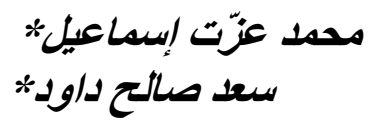

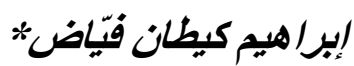

*وزارة العلوم و التكنولوجيا / دائرة علوم وبحوث الفيزياء

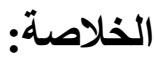

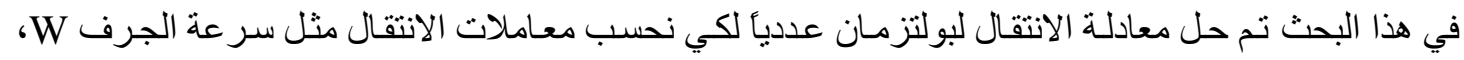

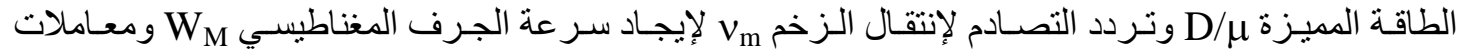

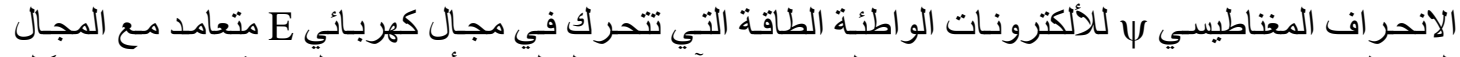

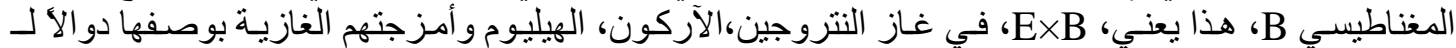
E/N

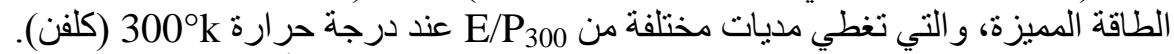

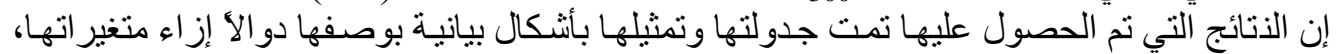

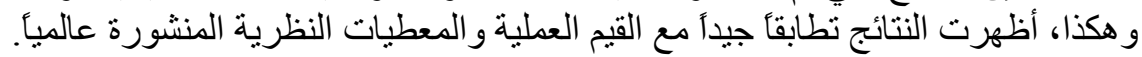

